\title{
ROBUST STABILIZATION OF A CONTINUOUS STIRRED TANK REACTOR MODEL
}

\author{
Radek Matušů
}
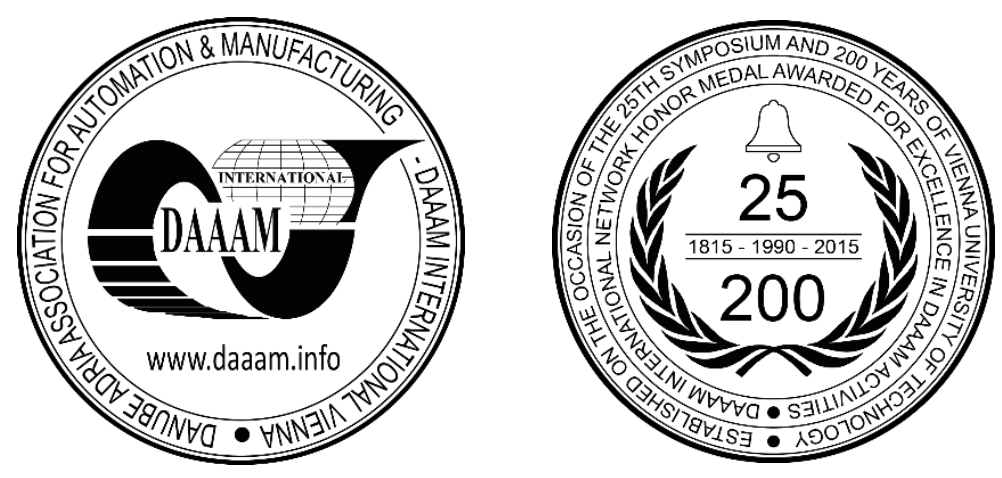

This Publication has to be referred as: Matusu, R[adek] (2016). Robust Stabilization of a Continuous Stirred Tank Reactor Model, Proceedings of the 27th DAAAM International Symposium, pp.0147-0150, B. Katalinic (Ed.), Published by DAAAM International, ISBN 978-3-902734-08-2, ISSN 1726-9679, Vienna, Austria DOI: $10.2507 / 27$ th.daaam.proceedings.022

\begin{abstract}
The main goal of this contribution is to outline an approach to robust stabilization of a continuous stirred tank reactor (CSTR) by means of PI controller. The linearized mathematical model of the CSTR with an exothermic reaction is supposed in the form of the fourth order interval system and its robust stabilization is based on combination of a method for calculating/plotting the stability boundary, the sixteen plant theorem and an algebraic approach to control design. The validity of the technique is verified on a simulative example of CSTR control.
\end{abstract}

Keywords: Robust stability; continuous stirred tank reactor; CSTR; interval system; PI controller; stability boundary; stability region.

\section{Introduction}

Chemical reactors belong among the most critical and interesting processes in all chemical engineering [1], [2]. They are frequently affected by complex behaviour and bounded with potential safety problems. From the viewpoint of control engineering, they represent the systems suitable for application of robust control [3], [4]. A common type of reactor is known as a continuous stirred tank reactor (CSTR) [1], [2]. The mathematical model of CSTR, robustly stabilized in this contribution, was constructed in [5]. Furthermore, the same work [5] presented stabilization of the CSTR by using the technique from [6], [7] and the pole-placement method. Besides, robust static output feedback control was applied to this CSTR in [8]. The robust stabilization in the paper [9] (which published the same results as can be found here) was based on the similar idea as in the contribution [5], but it used the alternative methods, namely the combination of the Kronecker summation method [10] and the algebraic approach to control design under the ring of proper and stable rational functions $\left(\mathrm{R}_{\mathrm{PS}}\right)$ [11], [12], [13], [14], [15]. The same combination and its application to a nonlinear electronic model described by the interval system have been already studied in [16], [17].

This contribution is focused on brief description of design of robustly stabilizing PI controllers for a CSTR in which an exothermic reaction occurs. The controlled CSTR is modelled as a fourth order interval system. The PI controller is designed by means of combination of a method for calculating/plotting the stability boundary, sixteen plant theorem and an algebraic approach. The robust stabilization is verified on a simulative example. The same results as in this work have been already published in the journal paper [9]. 


\section{Key results}

The controlled process is represented by a CSTR for hydrolysis of propylene oxide to propylene glycol. The detailed description of this CSTR can be found e.g. in [5], [8], [9]. Some physical parameters (reaction enthalpy, pre-exponential factor, and overall heat transfer coefficient) of the CSTR are not known exactly but they are assumed to vary within the intervals. This contribution adopts the mathematical model of the CSTR introduced in [5], where it was obtained in the linearized form of the fourth order interval transfer function:

$$
G(s)=\frac{[-0.0291,-0.0245] s^{2}+[-0.0199,-0.0127] s+[-0.000574,-0.0003549]}{s^{4}+[0.5801,0.903] s^{3}+[0.1002,0.2299] s^{2}+[0.0062,0.0142] s+[0.0001094,0.0002412]}
$$

where the input is the volumetric flow rate of the coolant, and the output is the temperature of the reacting mixture.

In the first step, the aim is to determine all possible robustly stabilizing PI controllers by means of plotting the stability boundary. It can be done e.g. via the Tan's (et al.) method [6], [7] or through the Kronecker summation method [10] and their combination with the sixteen plant theorem [3], [18]. A brief overview of these techniques can be found also in [19], [20]. The Fig. 1 shows the open areas of stabilizing or non-stabilizing pairs of proportional $\left(k_{P}\right)$ and integral $\left(k_{I}\right)$ gains of PI controller for the first of the sixteen Kharitonov plants [3], [18]:

$$
G_{1,1}(s)=\frac{-0.0245 s^{2}-0.0199 s-0.000574}{s^{4}+0.903 s^{3}+0.2299 s^{2}+0.0062 s+0.0001094}
$$

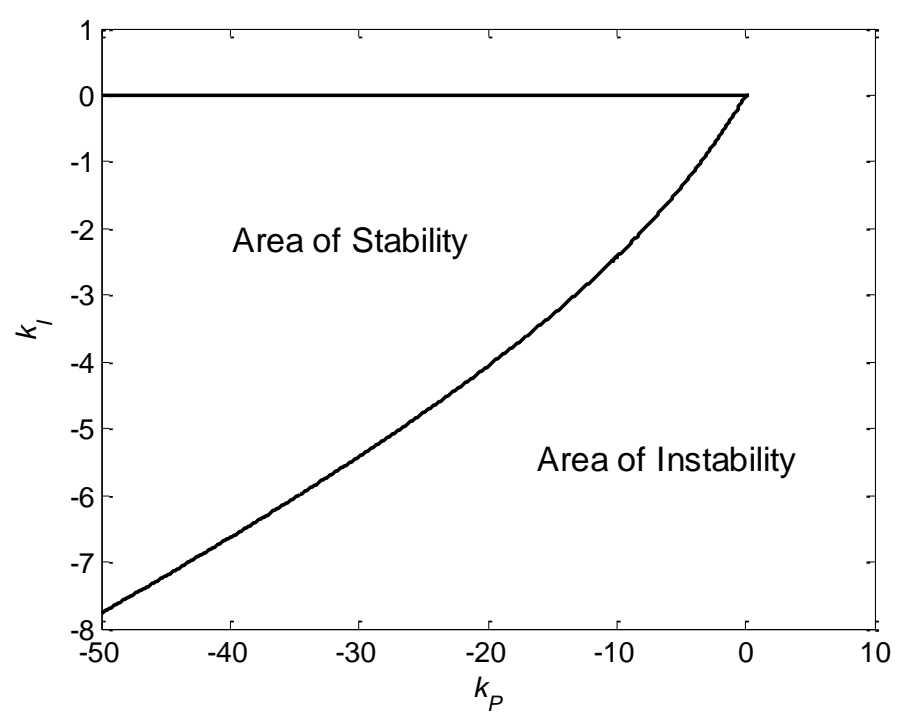

Fig. 1. Areas of stability/instability for the first Kharitonov plant (2)

The stability areas for all sixteen Kharitonov plants [3], [18] are plotted in Fig. 2. The intersection of these stability areas defines the region of stabilizing $\left(k_{P}, k_{I}\right)$ pairs for all sixteen Kharitonov plants together, i.e. it gives the robust stability region for the original interval plant (1). This region is zoomed and highlighted in Fig. 3.

The next step is to select a convenient PI controller from the obtained robust stability region. This contribution uses an algebraic approach based on general solutions of Diophantine equations in $\mathrm{R}_{\mathrm{PS}}$, Youla-Kučera parameterization of controllers, conditions of divisibility in $\mathrm{R}_{\mathrm{PS}}$, and additional single parameter tuning. The method is grounded in the ideas from [11], [12] and its details can be found e.g. in [13], [14], [15]. The PI controller designed for a nominal system obtained from the interval plant (1) is:

$$
C(s)=\frac{k_{P} s+k_{I}}{s}=\frac{-1.238 s-0.029706}{s}
$$

Obviously, the controller (3) lies inside the robust stability region from Fig. 3. The full design is described in [9].

Finally, the robust stability is confirmed and the control performance demonstrated in Fig. 4 which shows the set of output signals of the feedback control loop with designed PI controller (3) and 128 selected members of the interval family (1) with all variations of minimum or maximum values of each interval parameter. The level of reference signal was chosen just for the simulation purposes and it does not correspond to any real life values. As can be seen, the only one off-line tuned feedback PI controller with fixed coefficients can be successfully applied to robustly stabilize the fourth order interval model (1) of the CSTR. 


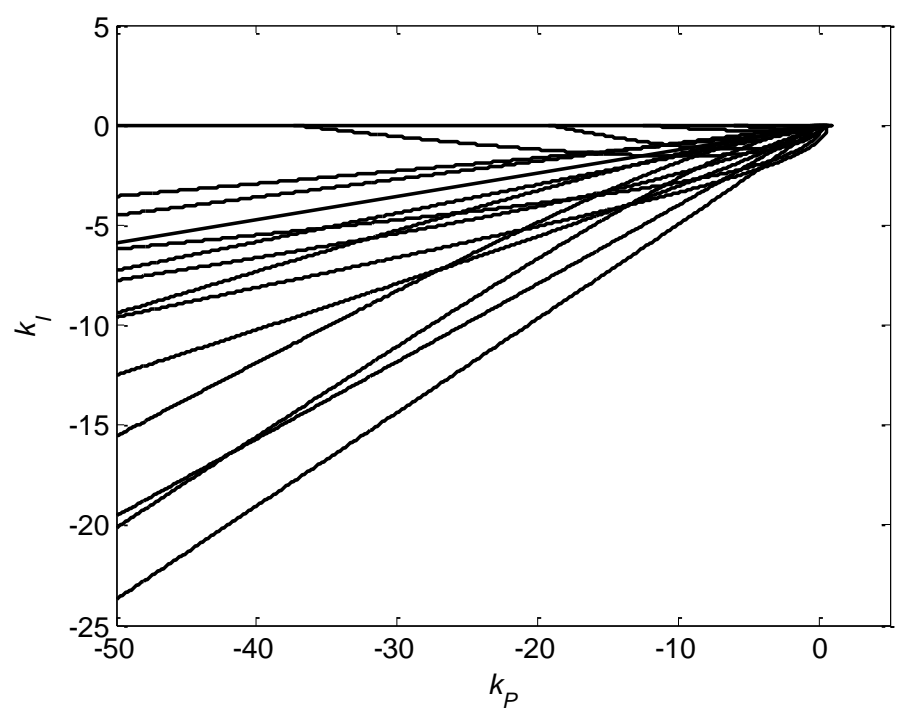

Fig. 2. Areas of stability for sixteen Kharitonov plants

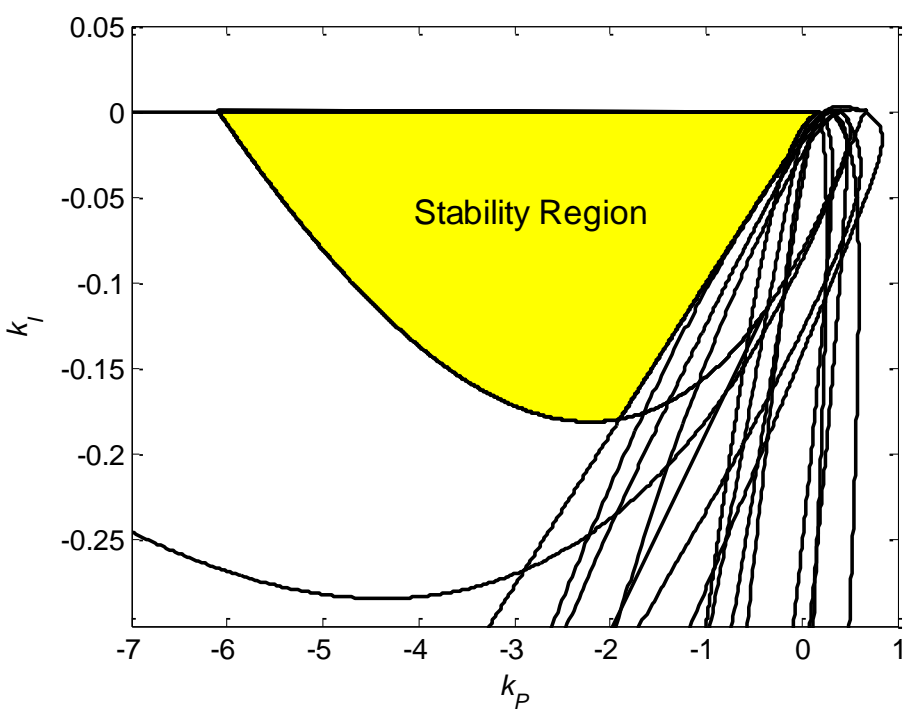

Fig. 3. Robust stability region for the interval plant (1)

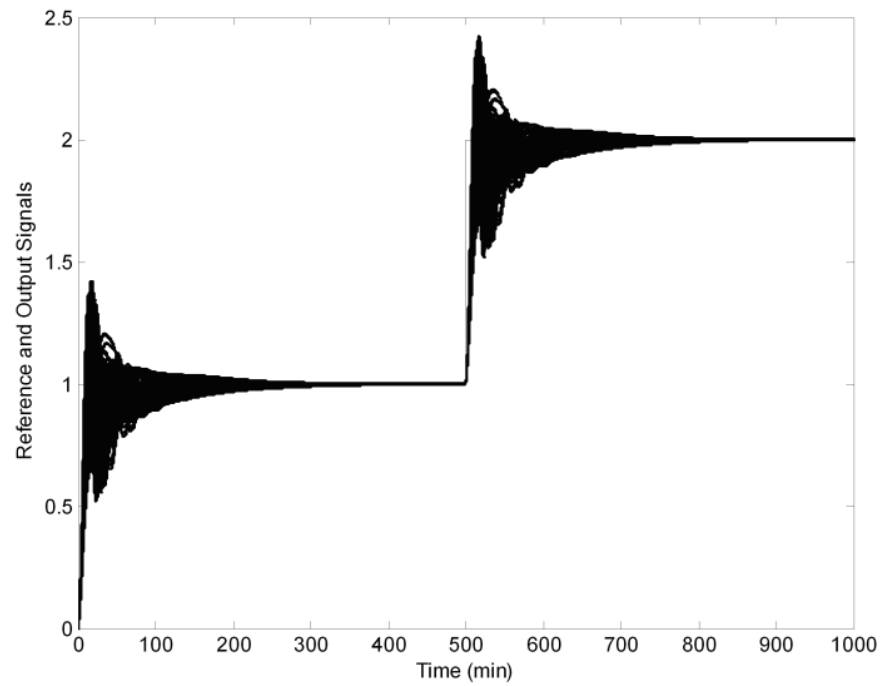

Fig. 4. Output (controlled) signals of 128 selected members of the interval family (1) 


\section{Conclusion}

This contribution was focused on brief description of an approach to robust stabilization of CSTR by means of PI controller. The CSTR with an exothermic reaction was considered as the fourth order interval plant and its robust stabilization was based on combination of a technique for calculating/plotting the stability boundary, the sixteen plant theorem and an algebraic approach to PI controller design. The validity of the method was verified through a simulative example with a set of CSTR control results.

\section{Acknowledgments}

This work was supported by the Ministry of Education, Youth and Sports of the Czech Republic within the National Sustainability Programme project No. LO1303 (MSMT-7778/2014).

\section{References}

[1] Luyben, W. L. (2007). Chemical Reactor Design and Control, John Wiley \& Sons, New Jersey, USA

[2] Antonelli, R. \& Astolfi, A. (2003). Continuous stirred tank reactors: easy to stabilise? Automatica, Vol. 39, No. 10, pp. 1817-1827

[3] Barmish, B. R. (1994). New Tools for Robustness of Linear Systems, Macmillan, New York, USA

[4] Vasičkaninová, A.; Bakošová, M.; Čirka, L. \& Kalúz, M. (2015). Comparison of Robust Control Techniques for Use in Continuous Stirred Tank Reactor Control, IFAC-PapersOnLine (8th IFAC Symposium on Robust Control Design ROCOND 2015), Vol. 48, No. 14, pp. 284-289

[5] Závacká, J.; Bakošová, M. \& Vaneková, K. (2010). Design of robust PI controllers for control of an exothermic chemical reactor, Proceedings of the 14th WSEAS International Conference on Systems, Corfu, Greece

[6] Tan, N. \& Kaya I. (2003). Computation of stabilizing PI controllers for interval systems, Proceedings of the 11th Mediterranean Conference on Control and Automation, Rhodes, Greece

[7] Tan, N.; Kaya, I.; Yeroglu, C. \& Atherton D. P. (2006). Computation of stabilizing PI and PID controllers using the stability boundary locus. Energy Conversion and Management, Vol. 47, No. 18-19, pp. 3045-3058

[8] Bakošová, M.; Puna, D.; Dostál, P. \& Závacká, J. (2009). Robust stabilization of a chemical reactor. Chemical Papers, Vol. 63, No. 5, pp. 527-536

[9] Matušů, R; Závacká, J.; Prokop, R. \& Bakošová, M. (2011). The Kronecker Summation Method for Robust Stabilization Applied to a Chemical Reactor. Journal of Control Science and Engineering, Vol. 2011, 7 p.

[10] Fang, J.; Zheng, D. \& Ren, Z. (2009). Computation of stabilizing PI and PID controllers by using Kronecker summation method. Energy Conversion and Management, Vol. 50, No. 7, pp. 1821-1827

[11] Vidyasagar, M. (1985). Control system synthesis: a factorization approach, MIT Press, Cambridge, Massachusetts, USA

[12] Kučera, V. (1993). Diophantine equations in control - A survey. Automatica, Vol. 29, No. 6, pp. 1361-1375

[13] Prokop, R. \& Corriou, J. P. (1997). Design and analysis of simple robust controllers. International Journal of Control, Vol. 66, No. 6, pp. 905-921

[14] Matušů, R. \& Prokop, R. (2011). Single-parameter tuning of PI controllers: Theory and Application. Journal of the Franklin Institute, Vol. 348, No. 8, pp. 2059-2071

[15] Matušů, R.; Vaneková, K.; Prokop, R. \& Bakošová, M. (2010). Design of robust PI controllers and their application to a nonlinear electronic system. Journal of Electrical Engineering, Vol. 61, No. 1, pp. 44-51

[16] Matušů, R.; Prokop, R.; Matejičková, K. \& Bakošová, M. (2010). Application of Kronecker Summation Method in Computation of Robustly Stabilizing PI Controllers for Interval Plants, Proceedings of the 14th WSEAS International Conference on Systems, Corfu, Greece

[17] Matušů, R.; Prokop, R.; Matejičková, K. \& Bakošová, M. (2010). Robust Stabilization of Interval Plants using Kronecker Summation Method. WSEAS Transactions on Systems, Vol. 9, No. 9, pp. 917-926

[18] Barmish, B. R.; Hollot, C. V.; Kraus, F. J. \& Tempo, R. (1992). Extreme point results for robust stabilization of interval plants with first order compensators. IEEE Transactions on Automatic Control, Vol. 37, No. 6, pp. 707-714.

[19] Matušů, R. (2008). Robust Stabilization of Interval Plants Using PI Controllers, Annals of DAAAM for 2008 \& Proceedings of the 19th International DAAAM Symposium, Trnava, Slovakia, pp. 831-832

[20] Matušů, R. \& Prokop, R. (2010). Two Approaches to Computation of Stabilizing PI Controllers, Annals of DAAAM for 2010 \& Proceedings of the 21st International DAAAM Symposium, Zadar, Croatia, pp. 487-488 